\title{
GANGLIONEUROMA: A RARE NEURAL CREST TUMOR
}

\author{
S. Ingale ${ }^{1}$ Pankaj Goyal2 ${ }^{2}$ Prakhar Mohaniya3 ${ }^{3}$ Rakesh Patil ${ }^{4}$, Siddharth Singh ${ }^{5}$
}

${ }^{1}$ Associate Professor, Department of Paediatrics, Krishna Institute of Medical College, Karad, Maharashtra. ${ }^{2}$ Resident, Department of Paediatrics, Krishna Institute of Medical College, Karad, Maharashtra. ${ }^{3}$ Resident, Department of Paediatrics, Krishna Institute of Medical College, Karad, Maharashtra. ${ }^{4}$ Resident, Department of Paediatrics, Krishna Institute of Medical College, Karad, Maharashtra. ${ }^{5}$ Resident, Department of Paediatrics, Krishna Institute of Medical College, Karad, Maharashtra.

ABSTRACT: Neuroblastoma, ganglioneuroblastoma and ganglioneuroma arise from sympathetic tissue in the neck, posterior mediastinum, adrenal gland, retroperitoneum and pelvis. Ganglioneuromas is a rare type of neural crest tumor which are commonly seen in childhood. They are highly differentiated benign tumors and are compatible with long-term disease free survival. Retroperitoneal localization is relatively frequent for these tumors. Due to its rarity and lack of specific radiological findings diagnosis is always postoperative. Here, we present a case of retroperitoneal ganglioneuroma which was diagnosed post operatively.

KEYWORDS: Neural Crest Tumor, Ganglioneuroma, Retroperitoneal.

HOW TO CITE THIS ARTICLE: S. Ingale, Pankaj Goyal, Prakhar Mohaniya, Rakesh Patil, Siddharth Singh. "Ganglioneuroma: A Rare Neural Crest Tumor". Journal of Evolution of Medical and Dental Sciences 2015; Vol. 4, Issue 88, November 02; Page: 15379-15381, DOI: $10.14260 /$ jemds/2015/2191.

INTRODUCTION: CASE REPORT: A 8-year-old boy presented with a 2-month history of pain abdomen and mass per abdomen which mother noticed 1 week back in the right lumbar region. Child had a good appetite and unaltered bowel and bladder habits, no h/o vomiting, fever, burning micturation. On physical examination his vital signs were normal. On per abdominal examination, about $8 \times 8 \mathrm{~cm}$ hard, non tender, non fluctuating mass was palpated at lower mid abdomen and right lumbar region. No hepatosplenomegaly, Ascitis was noted. Bowel sounds were present. Bilateral hernial orifices were normal. Bilateral testicles were normal in the scrotum.

All laboratory studies were within normal ranges and included Complete Hemogram, Liver Function Tests and Renal Function Tests. His chest Xray was normal. USG abdomen and pelvis showed a oval lobulated seen measuring $6.5 \times 4.5 \times 3.9 \mathrm{~cm}$ seen anterior to psoas muscle and abetting iliac vessel. Contrast enhancing computed tomography (CT) scan of the abdomen showed 74 (Cephalo-caudally) x 55 (Anterior-posterior) x 50 (Transverse) mms mixed attenuation well defined mass with some non homogenous contrast enhancement in the retroperitoneum superiorly lesion is displacing small bowel loops, inferiorly lesion is reaching upto the rectosigmoid junction, medially lesion is displacing aorta and inferior vena cava.

There is no evidence of bony erosion. Radiological features were suggestive of a Retroperitoneal Sacroma. Based on radiological findings a diagnostic laprotomy followed by total resection of the tumor was performed.

Financial or Other, Competing Interest: None.

Submission 08-10-2015, Peer Review 09-10-2015,

Acceptance 20-10-2015, Published 02-11-2015.

Corresponding Author:

Dr. Pankaj Goyal,

Room. No. 104, IHR Hostel,

Krishna Institute of Medical Sciences,

Karad-415110, Maharashtra

E-mail: drpankajgoyal2008@gmail.com

DOI:10.14260/jemds/2015/2191.
There was no evidence of Ascites/Peritoneal seedling. Grossly the tumor was a large encapsulated mass measuring $6.5 \times 5 \times 4.5 \mathrm{cms}$ outer surface was gray white gleasining and cut surface was solid, homogenous, dull gray white with whoreled appearance. Histologically, tumor was composed of Schwann cells, fibrous tissue and embedded within were large cells with abundant cytoplasm, large nuclei and prominent nucleoli (Ganglion cells).

There was no evidence of atypia/mitosis/necrosis. Based on the histopathological features a diagnosis of retroperitoneal ganglioneuroma was made. Post- operative period was uneventful, patient was discharged on 8th postoperative day.

DISCUSSION: Neuroblastomas, ganglioneuroblastomas and ganglioneuromas are tumors of the sympathetic nervous system that arise from the neuroectodermal cells derived from the neural crest cells.

These tumors differ in their degree of cellular and extracellular maturation. Neuroblastoma tend to be aggressive and occur in younger patients (Average 2 years), whereas Ganglioneuroma occur in older children (Average 7 years). ${ }^{1}$ Ganglioneuromas may occur spontaneously or during the therapy for neuroblastomas with either chemotherapy or radiation therapy.2,3 The reported incidence of ganglioneuroma is one per million population.

They are mostly sporadic but there are a few reports of ganglioneuromas associated with neurofibromatosis type II and multiple endocrinologic neoplasia type II. ${ }^{4}$ Ganglioneuromas can be found in the central nervous system or peripherally in the sympathetic system.

The most common localization is the posterior mediastinum followed by the retroperitoneal space. ${ }^{5}$

Retroperitoneal ganglioneuromas are usually nonfunctioning and asymptomatic until they reach large sizes in which case they cause symptoms due to local expansion and pressure on adjacent structures. 
2 Although symptoms of autonomic complications are usually seen in patients with hormone secreting ganglioneuromas, such symptoms may also be seen in patients with paravertebral ganglioneuromas compressing the autonomic fibers of the lumbosacral plexus. ${ }^{6}$

Also, there are functional ganglioneuromas that were found to release peptides such as vasoactive intestinal peptides (VIP), somatostatins and Neuropeptide Y (NPY) in the literature.

These tumors may cause some symptoms like diarrhea, sweating and hypertension related to those peptides. Since ganglioneuromas may release catecholaminergic peptides, surgeons should be aware of the possibility of hypertensive crisis during the surgery. ${ }^{7}$

Radiological examination also has no diagnostic value in most cases. Because of the rarity of retroperitoneal ganglioneuromas and absence of any characteristic radiologic features, imaging of these tumors is not reliable and diagnostic. ${ }^{8}$

Preoperative diagnosis of retroperitoneal ganglioneuroma is often difficult and the diagnosis is usually based on histopathological findings after surgical excision of the tumor. ${ }^{8}$ Although in some cases aspiration cytology with fine needle has been reported to be useful in the preoperative diagnosis of adrenal ganglioneuroma, since the tumoral tissue can contain fractions of less well differentiated areas, surgical exploration is required to achieve a definitive diagnosis and risk assessment. ${ }^{9}$

Grossly, they are large, encapsulated masses of firm consistency with an homogenous, solid, grayish white cut surface. Areas with different color or consistency should be sampled for microscopic examination with the suspicion of less differentiated foci.

They can be multiple and or associated with other independent types of neurogenous neoplasms such as neuroblastoma and pheocromocytoma. ${ }^{8}$ Microscopically, it consists of a spindle cell tumor resembling a neurofibroma but shows numerous ganglion cells. Microscopically ganglioneuromas have consists of a 2 spindle cell tumor composed of neuritic processes, Schwann cells and perineural cells and show numerous ganglion cells.8,10 Ganglioneuromas are typically slowly growing, benign tumors and have a tendency to remain clinically silent for a considerable time. Most patients have prolonged survival without any evidence of progression.
According to many authors, surgical excision is sufficient for the treatment. ${ }^{9}$ Preoperative or postoperative chemotherapy or radiotherapy have no value in the treatment except it was associated with ganglioneuroblastoma changes when there might be some role of chemotherapy. As it is a slow growing tumor, gross total surgical removal with preservation of organ functions is a feasible surgical option. ${ }^{2,3}$

In conclusion the ganglioneuroma arises from sympathetic ganglion which is a very rare disease and affects children more often than adults. ${ }^{1}$ It is a benign, slow growing tumor and since it is difficult to distinguish from other tumors due to lack of image findings diagnosis is always made histologically. ${ }^{2}$

\section{REFERENCES:}

1. Lonergan GJ, Schwab CM, Suarez ES, Carlson CL. Neuroblastoma, ganglioneuroblastoma, and ganglioneuroma: radiologic-pathologic correlation. Radiographics 2002; 22: 911-934.

2. Zugor V, Amann K, Schrott KM, Schott GE. Retroperitoneal ganglioneuroma. Aktuelle Urol 2005; 36 (4):349-352.

3. Moriwaki Y, Miyaka M, Yamamoto $\mathrm{T}$ et al. Retroperitoneal ganglioneuroma: a case report and review of the Japanese literature. Intern Med 1992; 31:82-85.

4. Jain M, Shubha BS, Sethi S, Banga V, Bagga D. Retroperitoneal ganglioneuroma: report of a case diagnosed by fine-needle aspiration cytology, with review of the literature. Diagn Cytopathol 1999; 21:194-196.

5. Chang CY, Hsieh YL, Hung GY, Pan CC, Hwang B. Ganglioneuroma presenting as an asymptomatic huge posterior mediastinal and retroperitoneal tumor. J Chin Med Assoc 2003; 66:370-374.

6. Hayes FA, Green AA, Rao BN. Clinical manifestations of ganglioneuroma. Cancer 1989;63 (6):1211-1214.

7. Gentile S, Rainero I, Luda E, Pinessi L. Autonomic dysfunction associated with multiple pelvic ganglioneuromas. Acta Neurol Scand 2001; 104:54-56.

8. Bjellerup P, Theodorsson E, Kogner P. Somatostatin and vasoactive intestinal peptide in neuroblastoma and ganglioneuroma: chromatographic characterization and release during surgery. Eur J Cancer 1995; 31A:481-485.

9. Rosai J. Chap 16: Adrenal gland and other paraganglia. In: Ackermans surgical pathology, vol 1, 8th edn. Mosby, St. Louis; 1996. pp 1015-58.

10. Radin R, David CL, Goldfarb H, Francis IR. Adrenal and extraadrenal retroperitoneal ganglioneuroma: imaging findings in 13 adults. Radiology 1997; 202:703-707.

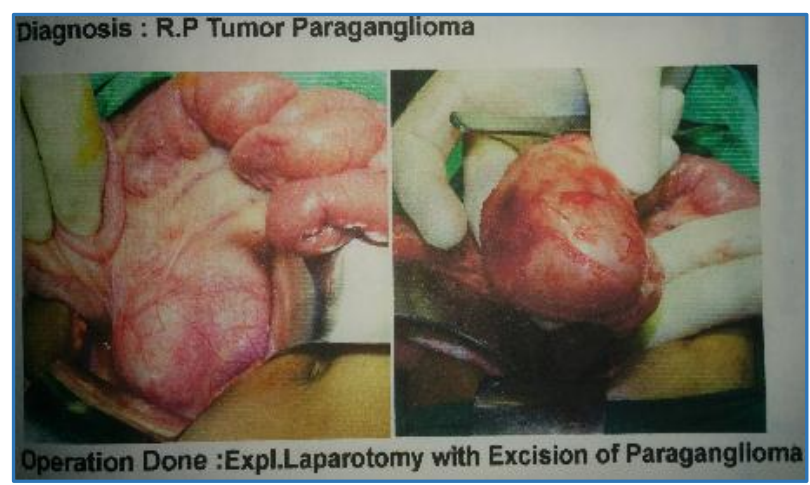

Fig. 1: post operative mass of ganglioneuroma 


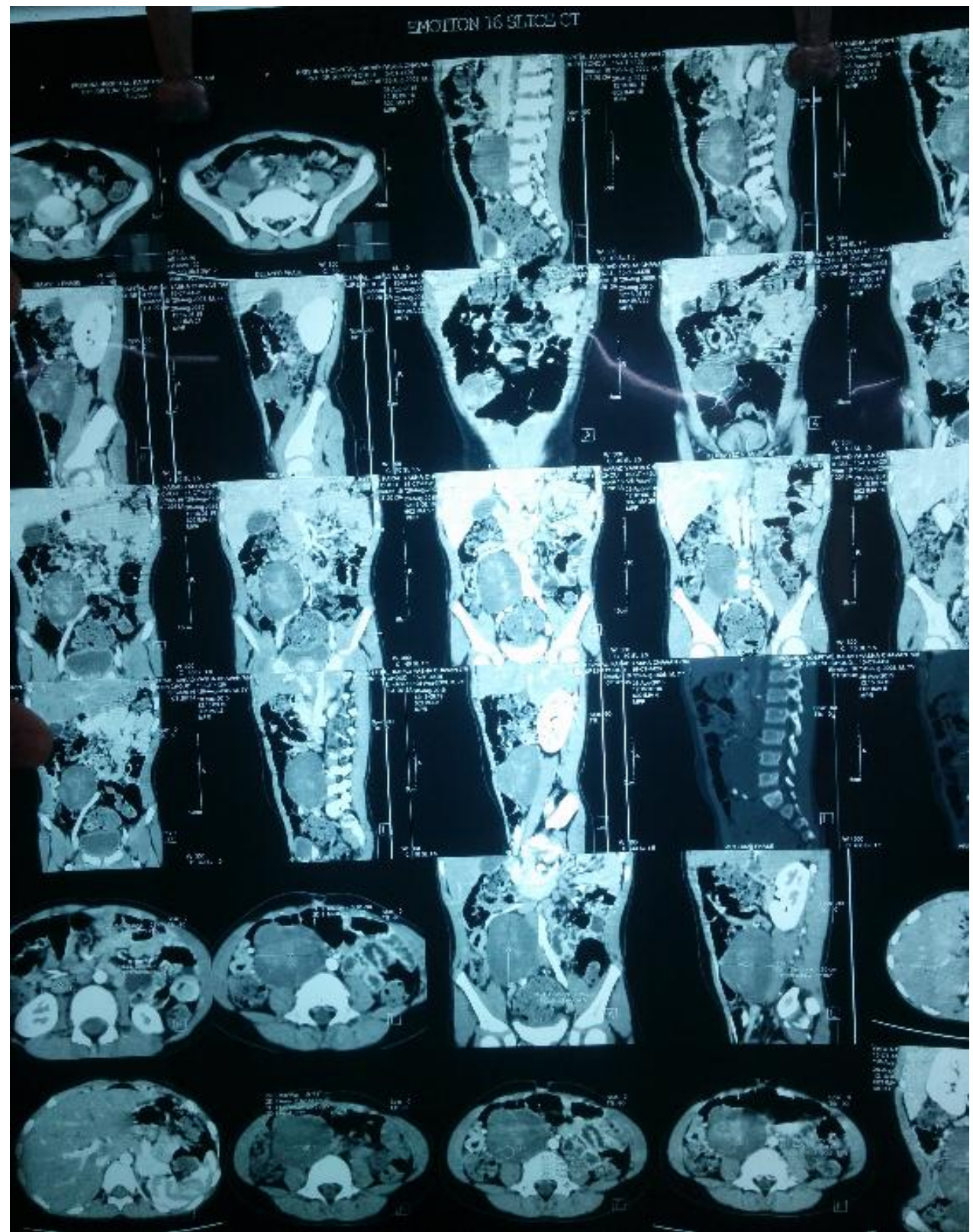

Fig. 2: CT Scan image Showing Mass Per Abdomen 